\title{
Vacuum-Assisted Hot-Forming Using Tailored Laminate Temperature
}

\author{
Tommy Grankäll1,2 (D) Per Hallander ${ }^{1,2}$ (D) Malin Åkermo ${ }^{\text {(D) }}$
}

Received: 16 July 2020 / Accepted: 1 December 2020 / Published online: 20 January 2021

(C) The Author(s) 2021

\begin{abstract}
A non-isothermal vacuum assisted hot-forming process using tailored laminate temperature is introduced. By using process simulation and manufacturing experiments, improved laminate quality is achieved compared to the standard hot-forming process. Furthermore, it is also shown that the manufacturing time in the clean room can be reduced to one tenth of the standard process time. In this study $8.4 \mathrm{~mm}$ thick quasi-isotropic laminates from unidirectional prepreg were laid up flat with an automatic tape laying machine and hotformed to a U-shaped laminate. The laminates were then cured in a concave mould with standard bag on the inside. A complete tailored temperature hot-forming cycle of $7.5 \mathrm{~min}$ produced a very good final laminate quality with a total thickness variation as low as $4.0 \%$ and without wrinkles or indications of porosity. With a 4 min hot-forming cycle the thickness variation was also acceptable at $8 \%$.
\end{abstract}

Keywords Forming $\cdot$ Prepreg $\cdot$ Simulation $\cdot$ Thickness variation $\cdot$ Wrinkles

\section{Introduction}

Hot-forming is an automation technique which can be used to decrease manufacturing cost for thermoset prepreg parts. With this technique, several prepreg plies are laid up flat and then formed simultaneously by heating the plies and forming them over a convex tool using a flexible membrane and vacuum. This process, also called multi-layer forming, can produce e.g. a U-shaped part. Properly executed the process has the benefit of reducing the variability that occurs in manual (by hand) lay-up. Previous work by Hallander et al. $[1,2]$ indicates that this method is valid for many cases but that it is considered to be a bottleneck in production with industrial standard hot-forming process times in the range of 40-60 min. The process time depends on several factors, both related to the equipment and the laminate. In research experiments, a hot-forming process with total cycle time of around $12 \mathrm{~min}$ has been reported for a thin $(2 \mathrm{~mm})$ laminate [3].

Tommy Grankäll

grankall@kth.se

1 Saab AB Bröderna Ugglas Gata, 58188 Linköping, Sweden

2 Department of Engineering Mechanics, KTH Royal Institute of Technology, Teknikringen 8, 10044 Stockholm, Sweden 
Quality issues relevant to the hot-forming process include wrinkles and thickness variation [1-8]. When forming a straight spar with U-shaped cross section on a convex surface the most common wrinkling defects include flange wrinkles on the inside of the laminate induced by laminate bending and corner wrinkles on the outside of the laminate induced by consolidation. Flange wrinkles appear due to inability of the prepreg layers to slide on top of each-other during forming and is governed by the interply friction during forming [3, 4, 8-10]. For prepreg, the uncured ply thickness often differs from the cured ply thickness $[11,12]$. This phenomenon is often called the material's bulk factor $[5,11$, 12]. During the manufacturing of a prepreg laminate several consolidation mechanisms will appear such as removal of air between plies, fibre tow impregnation and fibre bed compaction caused by percolation and shear flow. In a corner section this thickness difference will cause an arc length difference between laid-up ply length and the cured ply length which may result in wrinkles on a convex corner and bridging in a concave corner. The consolidation-driven wrinkles, described in [13-15], are often coupled to hand lay-up or materials with extreme bulk factors.

One parameter affecting both wrinkling and thickness variation during forming of prepreg is temperature. This is a contradiction for hot-forming since the elevated temperature is needed to avoid bending-induced wrinkles at the same time as it governs thickness variation [6]. Thickness variation developed during the forming process for a non-wrinkled laminate is most pronounced at corners. This is also referred to as corner thinning or corner thickening. One factor, definitely critical for laminate thickness variation in general is bagging for the cure. One approach to eliminate or reduce corner thinning has been to use an intensifier or caul plate and thereby try to distribute the cure pressure more evenly [16-19]. However, these can give other problems. Sjölander [7] investigated corner thinning when using a convex tool. It was shown that it is the hot-forming process rather than curing process that generates corner thinning. For the material used in the previous study [5], 15\% corner thinning has been reported related to standard hot-forming, i.e. measured before curing. Except for temperature, forming speed has been reported to have an effect on corner thickness [8]. Lower forming speed resulted in greater corner thinning.

The thickness variation in one part will negatively affect fit to the adjacent part. It is possible to avoid the fit problem by selecting the interface surface as tool surface on the parts. To enable having the tool surface on the outside of a hot-formed U-shaped part, it can be transferred to a concave tool prior to curing. The feasibility for hot-forming on a convex forming tool and subsequent curing in a concave cure tool has been shown [5]. In that study, the relationship between forming tool and cure tool dimensions was analyzed and developed for improved laminate quality. It was also shown that the change in corner thickness when using the combination of a convex tool for forming and subsequently a concave tool for curing, is different from when using either convex or concave tools for the entire manufacturing process (i.e. forming and cure). Consequently, a corner thinning from forming on a convex tool will not automatically cancel when curing in a concave cure tool.

In a recent experimental study by Hallander et al. [2] corner thinning was reduced by using a press-forming process with a temperature difference created between a cooled tool and a heated laminate giving a lower corner temperature and thus lower thinning. This paper is a continuation of that work. However, in this study a modified version of the standard vacuum-assisted hot-forming of a prepreg laminate is used. The aim is to investigate the process window for such process by modelling an optimised hotforming process where tailored forming temperature in the laminate is accomplished 
during heat-up and validate this process with experiments. The tailored forming temperature is a temperature difference across the laminate, e.g. between the flange area and corner area in a U-shaped part. The convex/concave tool combination from [5] is used. Furthermore, using the same material and laminate stacking sequence and cure process enables direct comparison of results. Success is identifying the opportunity to achieve a time-saving hot-forming process resulting in a wrinkle-free angled laminate with reduced corner thinning.

\section{Method}

Heat transfer simulation was used to establish a baseline for a suitable hot-forming set-up to achieve a tailored forming laminate temperature. Two types of experiments were performed to validate the simulation. The simulation was then extended to explore the sensitivity of the tailored laminate temperature forming technique.

\subsection{Simulation}

All simulation was performed using COMSOL software release 5.5 [20]. A two-dimensional model was created to estimate the temperature distribution in a flat laminate, i.e. to identify suitable baseline parameters for the tailored laminate temperature process. One half of the laminate used in the experiments was modelled, taking advantage of symmetry. Linear elements were used. The mesh resolution is shown in Fig. 1. Adequate mesh resolution was confirmed by convergence analysis, but the resolution was not optimised for minimum number of mesh elements.

The simulation was performed in four phases; heat-up, idle, forming and cool-down. In the heat-up phase the flange area of the flat laminate according to Fig. 1 was heated by conduction. Heating was either applied from one side, called single-sided heating or both sides, called double-sided heating. The rest of the surface was perfectly isolated. In the idle phase the laminate was exposed to the surrounding air via natural convection in a room temperature environment. This stage represents a delay between heat-up and forming which could be a transport period. The baseline idle time was set to $30 \mathrm{~s}$. The third phase was the actual forming. In this stage only the bottom of the laminate in the web area was in contact with a forming tool at room temperature and the rest of the bottom surface exposed to natural convection in a room temperature environment. The top surface and edge were isolated. The forming of the laminate was set to take $30 \mathrm{~s}$. The final stage was cool-down. In this stage the entire bottom side of the laminate was in contact with the forming tool and the rest of the laminate was exposed to forced convection in a room temperature environment (heat transfer coefficient $15 \mathrm{~W}^{*} \mathrm{~m}^{-2} * \mathrm{~K}^{-1}$ ). The cool-down, and thereby complete hot-forming operation, was considered concluded when the temperature in the middle of the flange $\left(\mathrm{F}^{0.5}\right.$ according to Fig. 1) fell below $28{ }^{\circ} \mathrm{C}$. The four phases and boundary conditions are summarised schematically in Fig. 2.

A typical standard hot-forming temperature is $65^{\circ} \mathrm{C}$ [1]. In our preceding study a minimum flange temperature of $50{ }^{\circ} \mathrm{C}$ was necessary in order to avoid wrinkling in hotforming with this material [2]. In that study a ten-degree lower corner temperature was observed to be beneficial for reduction of corner thinning. For the current study, the target flange temperature is $50{ }^{\circ} \mathrm{C}$ (at $\mathrm{F}^{0.5}$ according to Fig. 1) in combination with a corner temperature that is as low as possible, at forming start. 


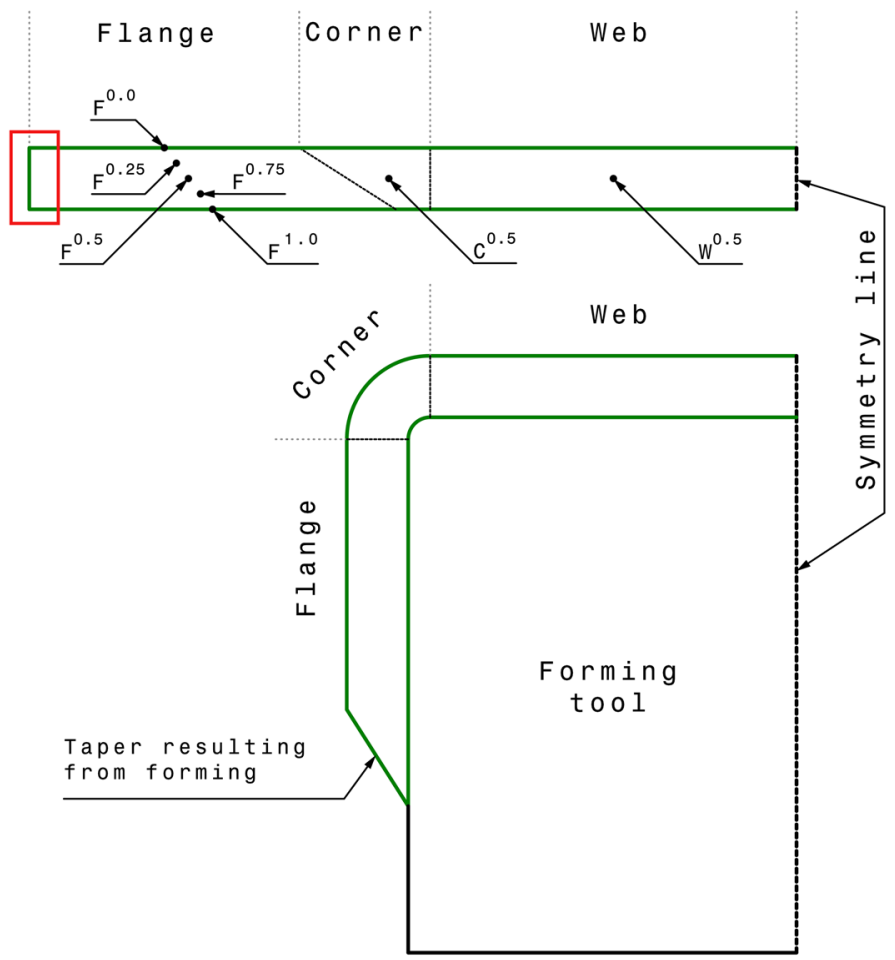

Fig. 1 Schematic cross section of the laminate areas and mesh example. The upper, flat geometry is the condition before forming which is used in the simulations. The lower geometry shows the cross section of the laminate after forming on the forming tool. Locations for temperature analysis in the simulations are shown $\left(\mathrm{F}^{0.0}-\mathrm{F}^{1.0}, \mathrm{C}^{0.5}, \mathrm{~W}^{0.5}\right)$. Symmetry line of the geometry is indicated

\subsection{Limitations and Assumptions}

The simulation is only for heat transfer. For this purpose, the geometry does not need to change. Different boundary conditions are used in the stages of the forming process. This is a trade-off motivated by both limitations in the used software and model size. Other software, e.g. Aniform [21], has the ability to change geometry during simulation, but then the temperature must be isothermal.

The physics for heat transfer is well understood. Thermal properties of composite materials are thoroughly described in an extensive review from 2016 [22]. One conclusion is that the thermal conductivity of composites is complex and difficult to model. Furthermore, it has been concluded that the rule-of-mixtures law does not provide accurate data, especially for the out-of-plane conductivity. While examples for thermal material properties of prepreg can be found [22-25], reliable data is scarce, especially when both in-plane and out-of-plane properties are required. Furthermore, no data is available for uncured laminates made from prepreg. There are studies where thermal conductivity is measured during cure but the low-temperature properties (i.e. when the materials are still un-cured) are estimated or interpolated [26, 27].

The in-plane thermal coefficient of the model was set to about half of the fibre thermal conductivity [22]. This is in line with reported values for similar materials [25]. 


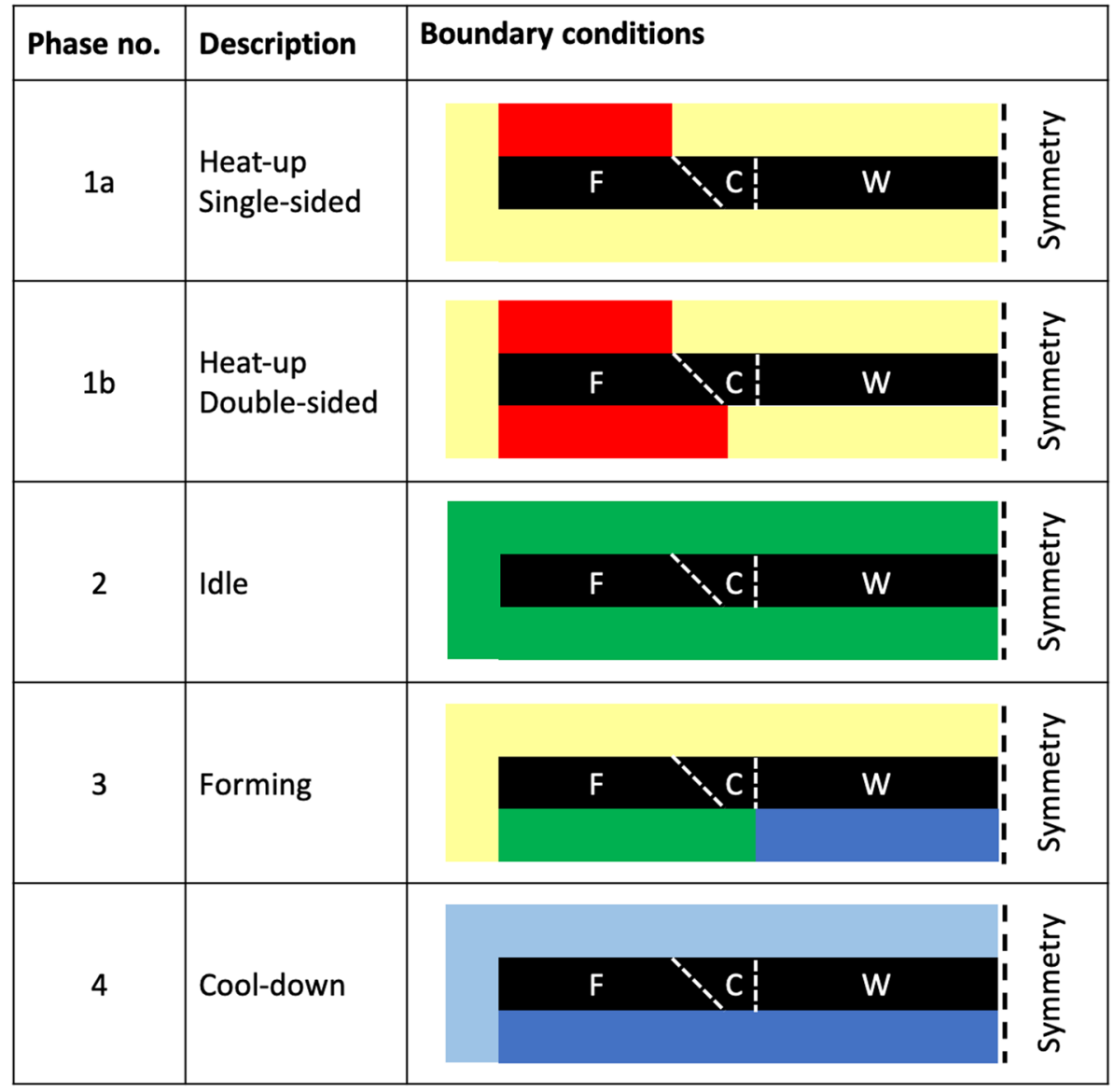

Fig. 2 Schematic representation of the four simulation phases with boundary conditions. Not to scale. Black represents the laminate with flange $(\mathrm{F})$, corner $(\mathrm{C})$ and web $(\mathrm{W})$ areas indicated with white letters and divided by dashed white lines. The model symmetry line is shown with black dashed line. Yellow represents perfect isolation. Red represents the conductive heat up elements at either $65^{\circ} \mathrm{C}$ or $70{ }^{\circ} \mathrm{C}$. Green represents natural convection and light blue represents forced convection, both with room temperature environment. Dark blue represents conductive cool-down elements at room temperature

Neat epoxy resin has a thermal conductivity of $0.25 \mathrm{~W}^{*} \mathrm{~m}^{-1} * \mathrm{~K}^{-1}$ [22]. Intuitively an uncured prepreg laminate has lower out-of-plane thermal conductivity than the cured laminate since it is not fully compacted. The in-plane properties are probably less affected. The out-of-plane thermal conductivity was set considering both the neat resin properties and reported through-thickness conductivity of cured laminates as well as the uncertain effect of an unconsolidated thickness. The resulting difference between in-plane and out-of-plane thermal conductivity is one order of magnitude. Furthermore, the thermal properties are considered constant in the forming temperature range.

Another unknown parameter for heat transfer simulation is contact conductance between tool and laminate. Perfect contact is assumed. The heat source and forming tool temperatures are assumed constant. 
The uncertain simulation parameters are further addressed in the Sensitivity study in chapter 4.1 .

\subsection{Material}

A Hexcel Hexply 6376/HTS aerospace grade, carbon fiber and epoxy resin prepreg was used for the experiments (and in the simulations). Nominal cured ply thickness is $0.131 \mathrm{~mm}$. The volume fraction is approximately $57 \%$. Basic resin properties are available in the product data sheet [28]. This material is a slow reaction aerospace grade prepreg with a cure temperature of $175{ }^{\circ} \mathrm{C}$ with $120 \mathrm{~min}$ final dwell. In the standard forming temperature range $\left(45^{\circ} \mathrm{C}-70{ }^{\circ} \mathrm{C}\right)$ crosslinking is minimal.

The thermal material properties for the quasi-isotropic laminate used for the simulations in this study are presented in Table 1 .

\subsection{Experiments}

Flat laminates with stacking sequence $\left((90,-45,0,45)_{2}\right)_{\mathrm{S}}$ were laid up using an automatic tape-layer machine (ATLM). The 16-ply laminates were cut to rectangles $300 \mathrm{~mm}$ by $250 \mathrm{~mm}$ using the ultrasonic knife on the machine. The laminates used in the experiments were built up from four 16-ply laminates, i.e. a total of 64 plies with a resulting nominal cured total thickness of $8.4 \mathrm{~mm}$. The complete stacking sequence is $\left(\left((90,-45,0,45)_{2}\right)_{\mathrm{S}}\right)_{4}$.

The geometry, lay-up method, material and stacking sequence of the laminates as well as curing process was identical to a previous study [5].

The laminate areas are called flange, corner and web as shown in Fig. 1. After forming, the U-shaped cross section has a $100 \mathrm{~mm}$ wide web and flanges about $75 \mathrm{~mm}$ high. The nominal inner corner radius is $3 \mathrm{~mm}$.

\subsubsection{Flat Laminate Temperature Measurements}

Forming with multiple thermocouples embedded in the middle of the laminate for correct temperature measurements will negatively affect the laminate quality. Instead temperature measurements were made in the flat condition. The thermocouple locations were selected based on locations indicated in Fig. 1. However, the locations at the top and bottom of the laminate were not used. Instead thermocouples were embedded in the interfaces between the 16 -ply laminates i.e. at $25 \%$ increments through the thickness, in locations $\mathrm{F}^{0.25}$ and $\mathrm{F}^{0.75}$ in the flange and $\mathrm{C}^{0.25}$ and $\mathrm{C}^{0.75}$ in the corner. After placing the thermocouples, the laminate was vacuum compacted to reduce the voids around the thermocouples. Laminate temperature was then measured during heating. The measurements were used to validate the material properties of the simulation model.

Table 1 Material parameters

\begin{tabular}{lll}
\hline Parameter & Value & Unit \\
\hline Heat capacity $(\mathrm{Cp})$ & 1300 & $\mathrm{~J}^{*} \mathrm{~kg}^{-1} * \mathrm{~K}^{-1}$ \\
Density & 1650 & $\mathrm{~kg}^{*} \mathrm{~m}^{-3}$ \\
Thermal conductivity in-plane & 3.5 & $\mathrm{~W}^{*} \mathrm{~m}^{-1 *} \mathrm{~K}^{-1}$ \\
Thermal conductivity out-of-plane (k33) & 0.35 & $\mathrm{~W}^{*} \mathrm{~m}^{-1} * \mathrm{~K}^{-1}$ \\
\hline
\end{tabular}




\subsubsection{Tailored Laminate Temperature Hot-Forming}

Nine U-shaped laminates were manufactured using the tailored laminate temperature hotforming process. The target was a forming temperature of $50{ }^{\circ} \mathrm{C}$ for the control point $\mathrm{F}^{0.5}$ shown in Fig. 1. The temperature was monitored by one thermocouple in this location at one edge of the laminate. The heat source temperature was either $65{ }^{\circ} \mathrm{C}$ or $70{ }^{\circ} \mathrm{C}$. When single-sided heating was used, the heated side was either turned to face upwards or downwards during forming. The temperature at forming start and process time was recorded. The laminate numbers and process variables are shown in Table 2.

The heat-up phase was performed by placing pre-heated solid aluminium blocks with straight edges and even temperature on the specific areas of the laminate. Thereby, it was easy to maintain a distinct temperature and distinct area for the heating, matching the temperature and heating area in the simulation (as illustrated in Fig. 1 and Fig. 2). After heating the laminates were placed on a forming tool which was at room temperature. Forming was then carried out in a standard vacuum table with a Mosites \#1453 silicon forming membrane. As for the simulation, the idle time, i.e. when the laminate was moved and consumables were applied, was timed to $30 \mathrm{~s}$. The actual forming was also $30 \mathrm{~s}$.

Thickness measurements of the uncured laminates was performed using a digital Vernier calliper. The flat flange and web areas of the U-shaped laminate provide no difficulties for measurement. Several measurement points per laminate and area were taken.

The thickness in the radius is somewhat more difficult to measure accurately. The midradius thickness was gauged by placing a tight tolerance steel cylinder on the inside of the laminate. The calliper was applied to the cylinder surface and laminate outside as shown in Fig. 3. The cylinder radius was selected to be slightly less than the inner radius of the formed laminate. Using this technique, the flat area thickness and the radius area thickness are gauged as equally as possible.

The formed samples were moved from the convex forming tool and cured in a concave composite mould tool with only a standard bag on the inside. The cure cycle was $0.7 \mathrm{MPa}$ at $180{ }^{\circ} \mathrm{C}$ with full vacuum in the bag.

After curing, the laminates were visually inspected before trimming. A cut was then made in the middle of the laminate and a $30 \mathrm{~mm}$ long section was extracted from one of the halves. The sections were then inspected in detail. Shape was measured optically by GOM ATOS triple scan equipment [29]. The spring-in angle was measured on the $30 \mathrm{~mm}$ long sections of the samples with untrimmed flanges. Evaluation of measurement was made by

Table 2 Summary of laminates for experiments with process parameters

\begin{tabular}{llll}
\hline $\begin{array}{l}\text { Laminate } \\
\text { number }\end{array}$ & Heating & $\begin{array}{l}\text { Heat source tem- } \\
\text { perature }\left[{ }^{\circ} \mathrm{C}\right]\end{array}$ & $\begin{array}{l}\text { Heated side } \\
\text { up or down }\end{array}$ \\
\hline$\# 1$ & Single-sided & 65 & $\mathrm{Up}$ \\
$\# 2$ & Single-sided & 65 & $\mathrm{Up}$ \\
$\# 3$ & Single-sided & 65 & $\mathrm{Up}$ \\
$\# 4$ & Single-sided & 65 & Down \\
$\# 5$ & Single-sided & 70 & Down \\
$\# 6$ & Double-sided & 65 & - \\
$\# 7$ & Double-sided & 65 & - \\
$\# 8$ & Double-sided & 65 & - \\
$\# 9$ & Double-sided & 70 & - \\
\hline
\end{tabular}


Fig. 3 Measurement principle of radius thickness. A Vernier calliper combined with a steel cylinder at inner radius (coloured blue for increased visibility)

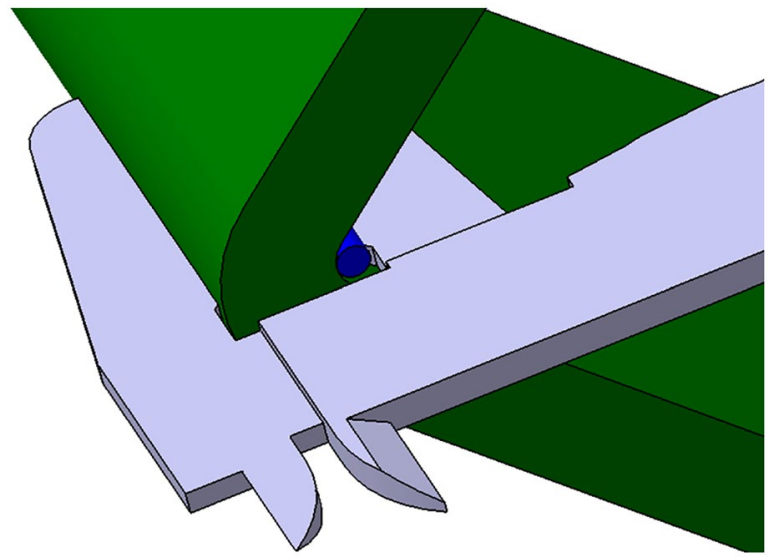

the GOM Inspect software [30]. The angle was evaluated with the full surface of the flange and web as reference.

One cross section surface from the middle of all samples was polished and micrographed by an Olympus BX53M microscope [31]. The micrographs were evaluated with regards to wrinkles, porosity and thicknesses, in the Olympus Stream Basic software [32].

\subsection{Results}

The total process times for the tailored temperature hot-forming process from simulation and experiments are shown in Table 3. The time for experiment \#6 was not recorded due to an error. The total process time includes heat-up time to achieve the forming temperature, an idle time of $30 \mathrm{~s} \mathrm{(e.g.} \mathrm{for} \mathrm{transport} \mathrm{of} \mathrm{the} \mathrm{laminate} \mathrm{and} \mathrm{application} \mathrm{of} \mathrm{consumables),} \mathrm{forming} \mathrm{for} 30 \mathrm{~s}$ and then cool-down time to a laminate temperature of $28^{\circ} \mathrm{C}$. As described in Sect. 2, the targeted temperature at location $\mathrm{F}^{0.5}$ is equal to $50{ }^{\circ} \mathrm{C}$ at forming start. This was achieved for laminates \#3, \#4 and \#7. However, in the experiments this temperature varied slightly for the rest of the laminates. The actual (resulting) temperatures are listed in Table 3. In order to be able to compare between simulation and experiments, the heat-up time in the simulations were adjusted to give

Table 3 Summary of total process times and resulting forming temperatures for experiments. Refer to Fig. 1 for temperature measurement location and Table 2 for process parameters

\begin{tabular}{llll}
\hline $\begin{array}{l}\text { Laminate } \\
\text { number }\end{array}$ & $\begin{array}{l}\mathrm{F}^{0.5} \text { temperature at } \\
\text { forming start }\left[{ }^{\circ} \mathrm{C}\right]\end{array}$ & \multicolumn{2}{c}{ Total process time $[\mathrm{s}]$} \\
\cline { 3 - 4 } & & Simulation & Experiments \\
\hline$\# 1$ & 53 & 563 & 601 \\
$\# 2$ & 51 & 506 & 523 \\
$\# 3$ & 50 & 474 & 460 \\
$\# 4$ & 50 & 474 & 445 \\
$\# 5$ & 52 & 457 & 460 \\
$\# 6$ & 53 & 311 & - \\
$\# 7$ & 50 & 281 & 262 \\
$\# 8$ & 49 & 272 & 250 \\
$\# 9$ & 45 & 238 & 228 \\
\hline
\end{tabular}


the same forming temperatures as for the experiments. The results are detailed in the following sections. Refer to Table 2 for the process parameters.

\section{Simulation Results}

A plot of the simulation with single-sided heating of the flange from the top is shown in Fig. 4. The plot shows three positions; top, middle and bottom $\left(\mathrm{F}^{0.0}, \mathrm{~F}^{0.5}\right.$ and $\left.\mathrm{F}^{1.0}\right)$ through the thickness of the laminate in the position indicated in Fig. 1.

In the heat-up phase the through-thickness temperature range is initially equal to the difference between room temperature and the heat source temperature. The top surface $\left(\mathrm{F}^{0.0}\right)$ instantly reaches the heat source temperature. In the bottom $\left(\mathrm{F}^{1.0}\right)$ and middle $\left(\mathrm{F}^{0.5}\right)$ of the laminate, temperatures increase steadily but at slightly different rates. Achieving the targeted forming start temperature requires $238 \mathrm{~s}$ of single-sided heating. The temperature difference is then about 20 degrees through the laminate. After $30 \mathrm{~s}$ of idle time the temperature difference is reduced to 7 degrees due to internal heat transfer within the laminate and convection towards the surrounding air the middle of the laminate is $50{ }^{\circ} \mathrm{C}$. During $30 \mathrm{~s}$ of forming the temperature difference decrease even further, with a minimum of 3 degrees. Entering the last phase, as the entire laminate comes into contact with the forming tool the bottom surface of the laminate cools down instantly. The cool-down phase is $176 \mathrm{~s}$ and the hot-forming process is completed in $474 \mathrm{~s}$.

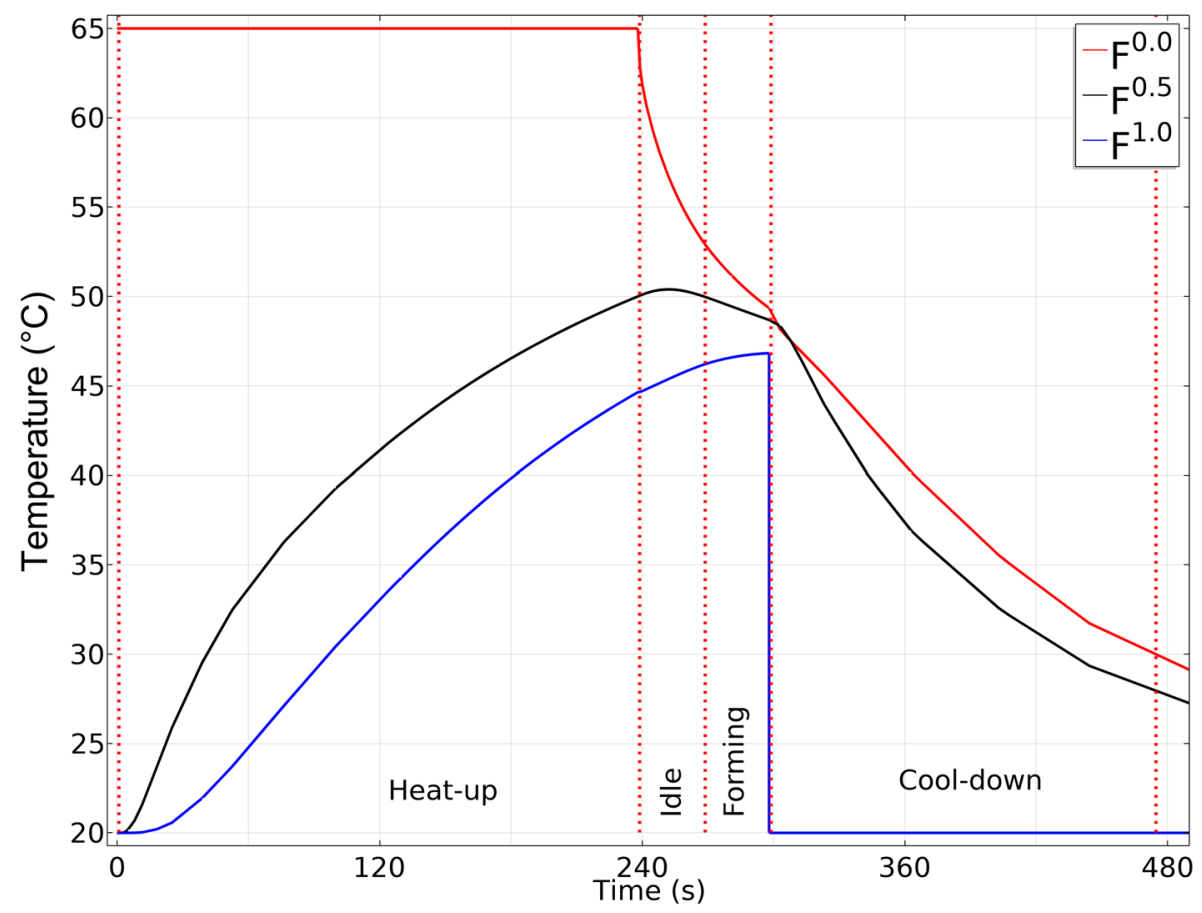

Fig. 4 Hot-forming using single-sided heating from the top in flange area of the laminate. The four phases of the process indicated with vertical, red dotted lines. Plots of three positions through the thickness of the laminate $\mathrm{F}^{0.0}, \mathrm{~F}^{0.5}, \mathrm{~F}^{1.0}$ according to Fig. 1 


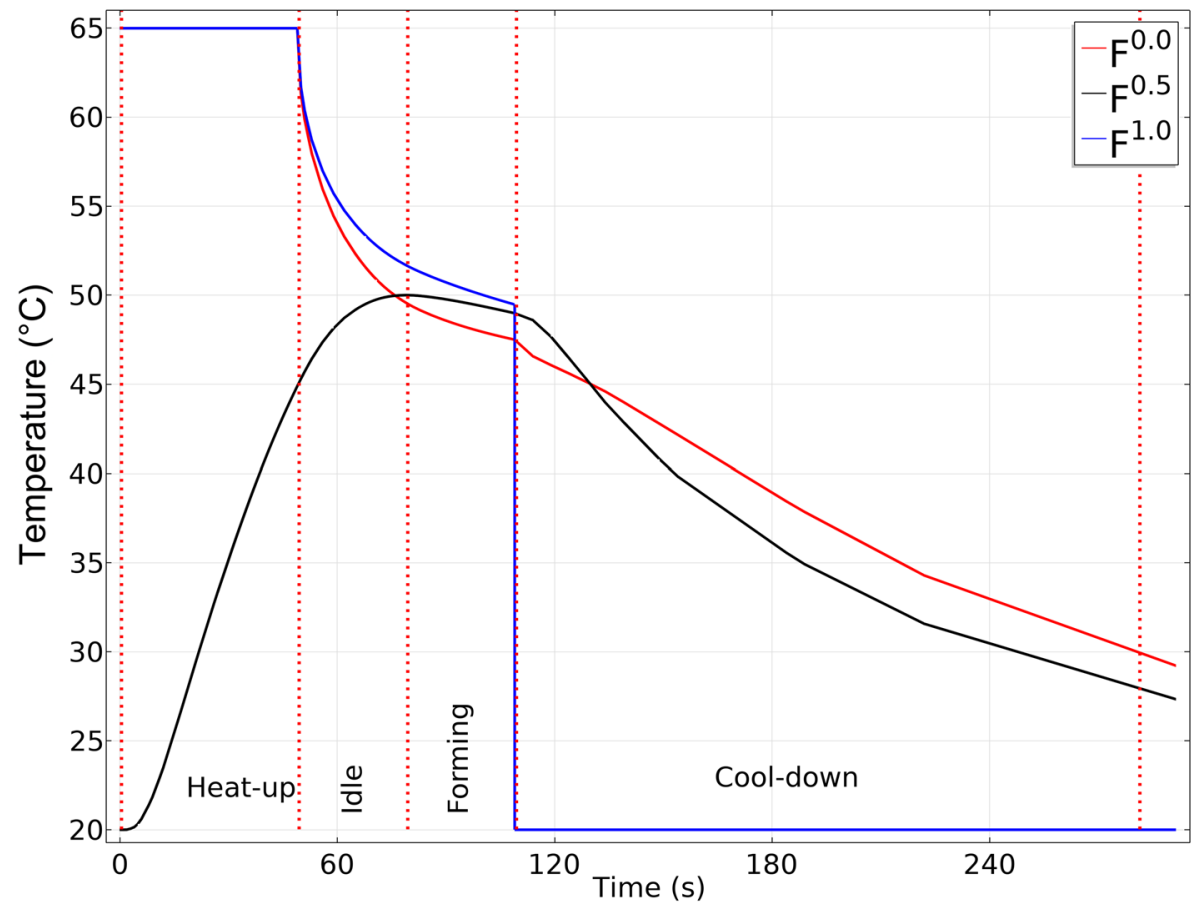

Fig. 5 Forming process simulation with double-sided heating of the flange. The four phases of the process indicated with vertical, red dotted lines. Plots of three positions through the thickness of the laminate $\mathrm{F}^{0.0}$, $\mathrm{F}^{0.5}, \mathrm{~F}^{1.0}$ according to Fig. 1

Figure 5 shows double-sided heating of the flange area. The upper side of the laminate cools down slightly more rapidly than the bottom during the idle period since the natural convection is higher from the top surface. The heat-up time is reduced to $49 \mathrm{~s}$. Identical compared to the single-sided heating, the temperature difference through the laminate at this point of the process is 20 degrees. However, at forming start, the temperature difference through the laminate is only 3 degrees. The cool-down phase is $172 \mathrm{~s}$. The entire process is $281 \mathrm{~s}$.

In the surface plots shown in Fig. 6 the location $\mathrm{F}^{0.5}$ (ref Fig. 1) is at $50{ }^{\circ} \mathrm{C}$ for both heating options. From the black isothermal lines, it is clear that the temperature gradient through the thickness of the laminate is different for single- and double-sided heating.

Single sided heating

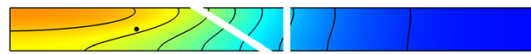

Double sided heating

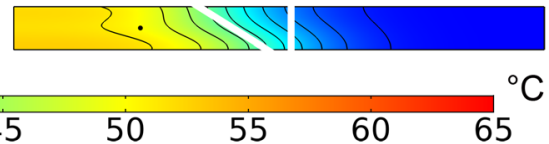

Fig. 6 Surface temperature at forming start for single-sided flange heating (from the top surface) on the left-hand plot, and double-sided flange heating on the right-hand plot. Isothermal lines in black show temperature gradient through the laminate. White lines show the border between the different areas of the laminate. Middle of flange $\left(\mathrm{F}^{0.5}\right)$ positions according to Fig. 1 are indicated with black dots 

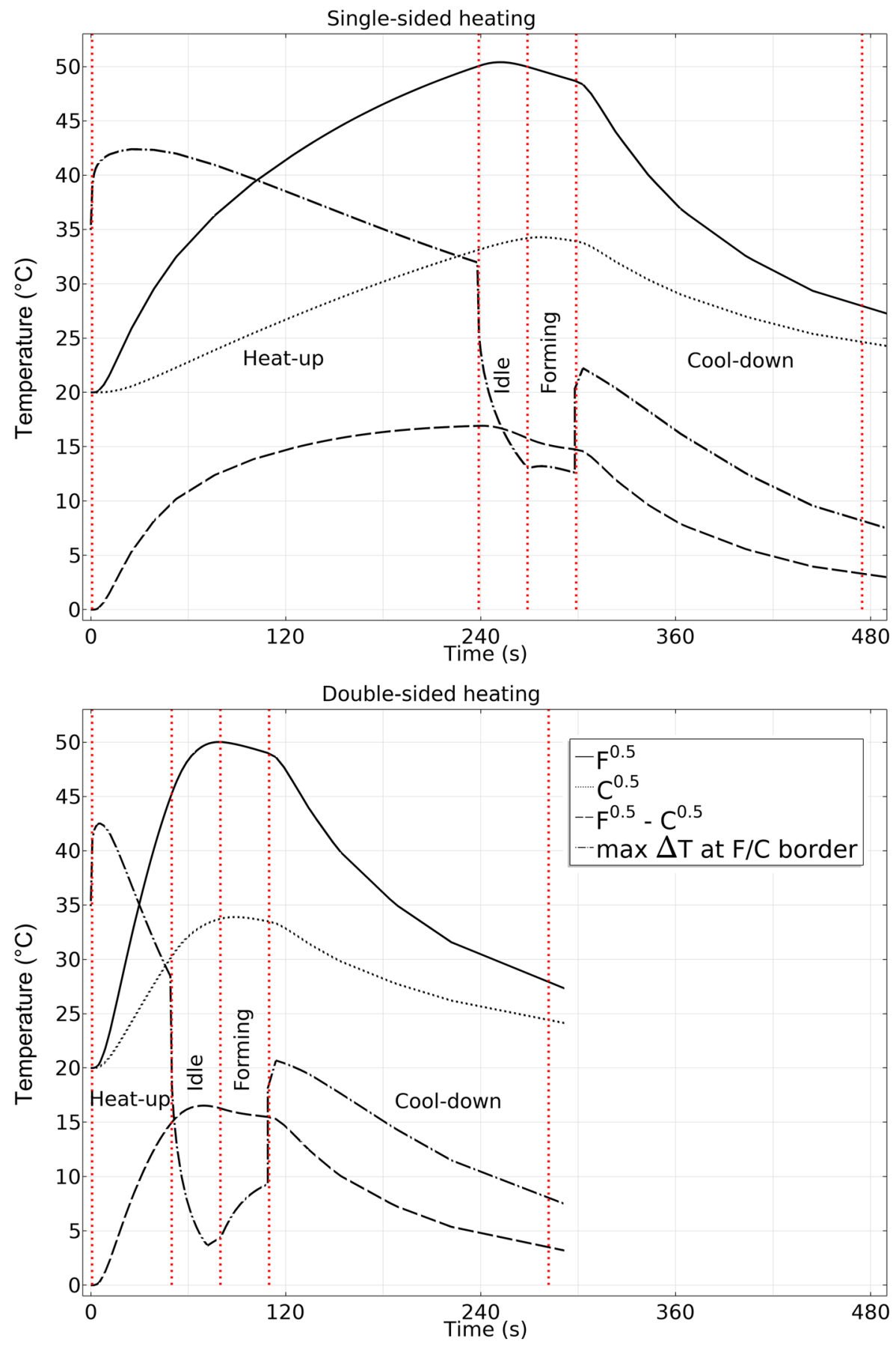

Fig. 7 Baseline-forming process with single-sided heating in upper graph and double-sided heating in lower graph. Solid lines show flange temperature at $\mathrm{F}^{0.5}$ and dotted lines show corner temperature at $\mathrm{C}^{0.5}$. Dashed lines show the difference between $\mathrm{F}^{0.5}$ and $\mathrm{C}^{0.5}$. Dash-dot lines show the maximum temperature variation through the thickness of the laminate at the border between the flange and corner areas. Positions according to Fig. 1. Legend valid for both graphs 
Figure 7 shows the baseline-forming process for single- and double-sided heating with more details across the laminate. Solid lines show the flange temperature at $\mathrm{F}^{0.5}$ and dotted lines the corner temperature at $\mathrm{C}^{0.5}$ (ref Fig. 1). The dashed lines show the result of the tailored heating, i.e. the difference between flange and corner. The dash-dot lines show the maximum temperature variation through the thickness of the laminate at the border between the flange and corner areas.

The results show that double-sided heating gives a shorter forming cycle compared to singlesided heating. It is also possible to see that the length of the cool-down phase is almost identical in both cases. The temperature difference between flange and corner is almost identical, $17{ }^{\circ} \mathrm{C}$, regardless of single-sided or double-sided heating. The through-thickness temperature variation at the flange to corner border is at least 13 degrees for single-sided heating while it can be as low as 4 degrees for double-sided heating.

\subsection{Experimental results}

The average uncured thickness for flat areas after forming was $9.3 \mathrm{~mm}$ and for the corner the average was $9.0 \mathrm{~mm}$. This is $10.9 \%$ and $7.3 \%$ respectively above nominal. Thus, the uncured thickness difference is only $3.6 \%$.

After curing no visible defects were found on the surfaces of the samples. Figure 8 shows cured thickness deviation from nominal and forming temperatures for all samples. The thickness values show maximum and minimum values for each sample and the average of the thickness in the middle of both corners in each sample. The samples heated from

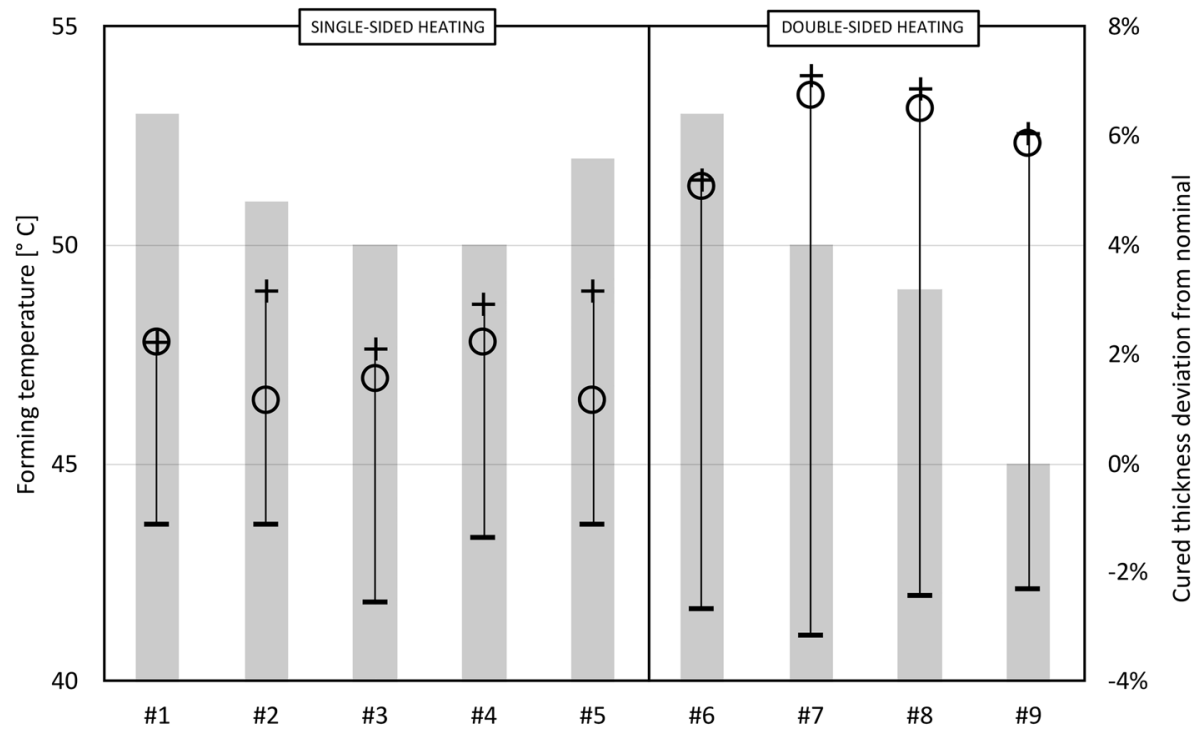

Forming temperature + Sample max thickness - Sample min thickness $\mathbf{O}$ Corner average thickness

Fig. 8 Left-hand side vertical axis and grey bars show forming temperature ( $F^{0.5}$ according to Fig. 1). Right-hand side vertical axis show cured thickness deviation from nominal. Series with plus, minus and circle markers show minimum and maximum thickness values for each laminate and the average of the thickness in the middle of both corners in each sample. Single-sided or double-sided heating indicated 

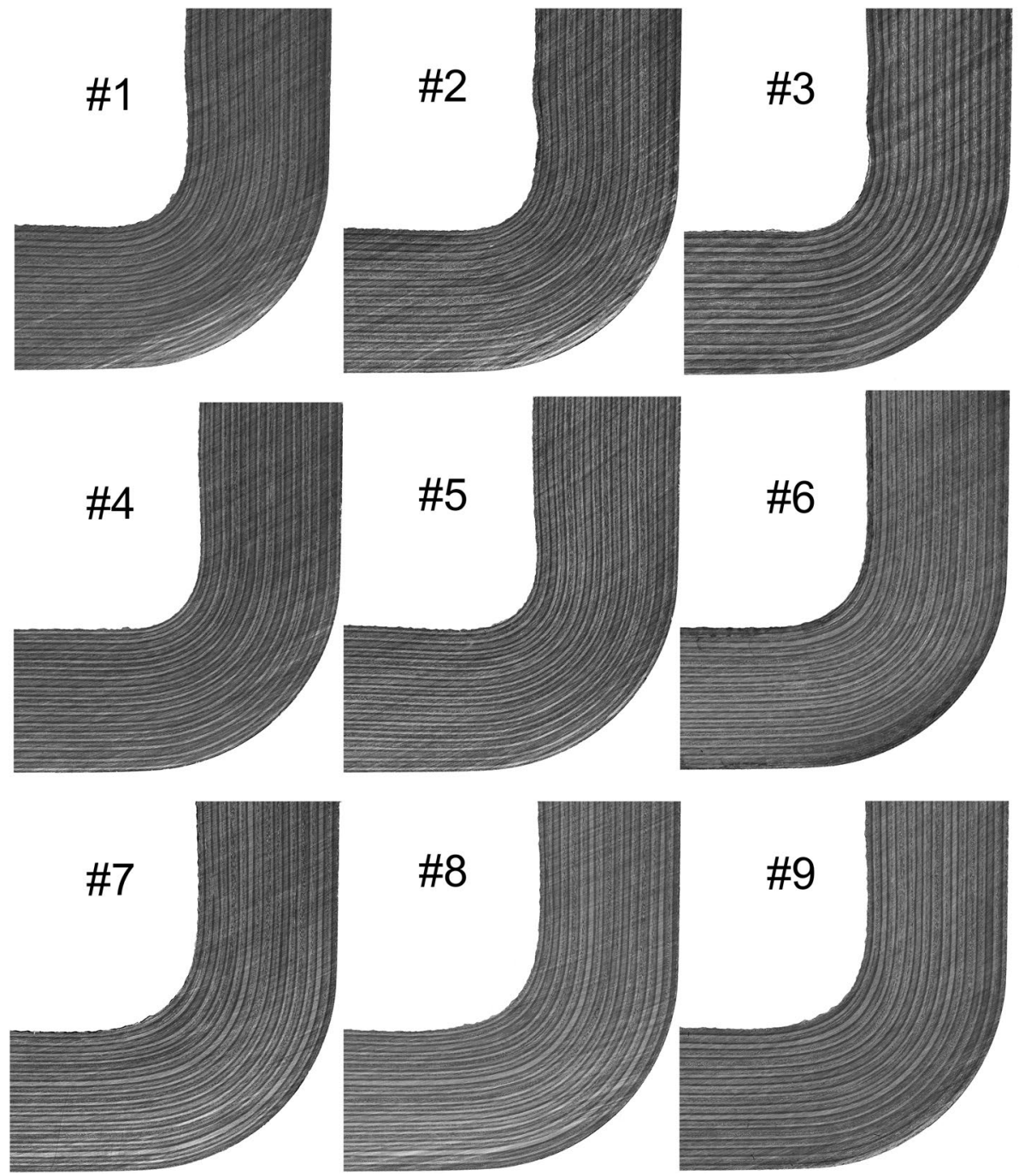

Fig. 9 Detailed view of corners. Webs are horizontal and flanges are vertical. Micrographs from cross-sections taken at the middle of each laminate

both sides showed a greater thickness variation and especially thicker corners. This corner thickening occurs during curing as the laminate thickness decrease and cause the plies to bridge in the corner.

Figure 9 shows the right-hand side corner of all samples. Samples \#1 and \#5 show a slight thickness variation with minimum thickness at the border between flange and corner. Samples \#2 and \#3 also show this thickness variation and a slight flange wrinkle. Sample \#4 is close to perfect with thickness variation within $\pm 1.5 \%$. Samples \#6-\#9 show corner thickening. No indications of porosity have been observed for any of the samples. 


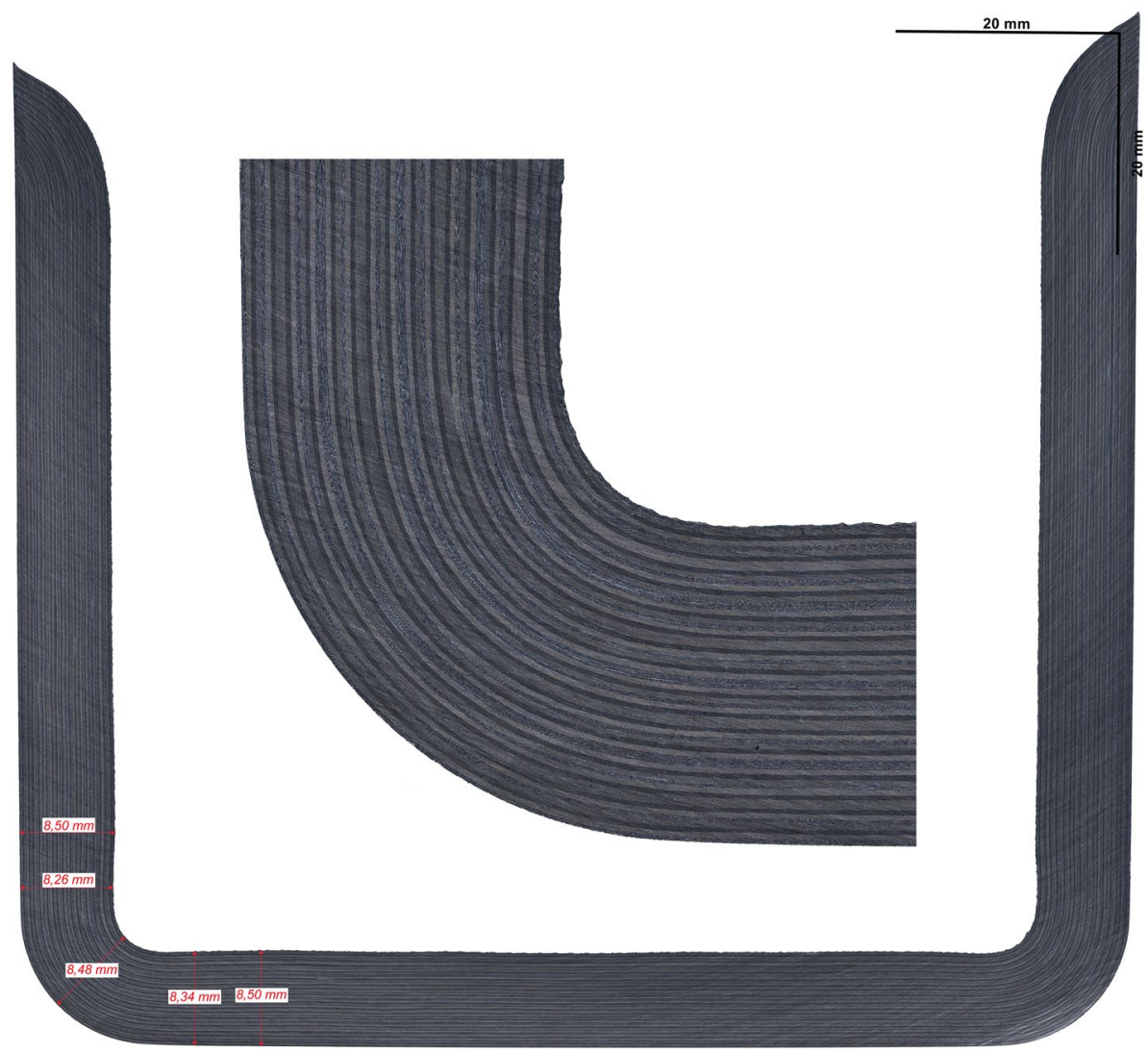

Fig. 10 Micrograph of entire cross section from middle of Laminate \#1 made with tailored laminate temperature hot-forming with single-sided heating. Detailed view of the left corner shown in the middle

Comparing laminates \#3 and \#4, where single-sided heating was used and the targeted forming temperature was reached, it was found that it was beneficial from a laminate quality perspective to have the heated surface facing downwards during forming.

A micrographed cross-section from the middle of laminate \#1 is shown in Fig. 10. This laminate has a ten minutes hot-forming process time which is the longest of this study. The laminate quality is very good, without wrinkles or indications of porosity. However, a slight thickness variation is present around the corner. Entire cross sections of all samples are shown in Appendix 1.

Figure 11 shows formed laminate \#9. This sample has the shortest hot-forming process time in this study with just below $4 \mathrm{~min}$. It also has the lowest forming temperature. The uncured laminate has similar wrinkle indications in both the flanges and the web area close to the corner. These wrinkles have completely disappeared after curing and there is no trace of resin rich areas.

The average spring-in angle of the samples is 1.3 degrees with a range of 1.2 to 1.4 degrees. 


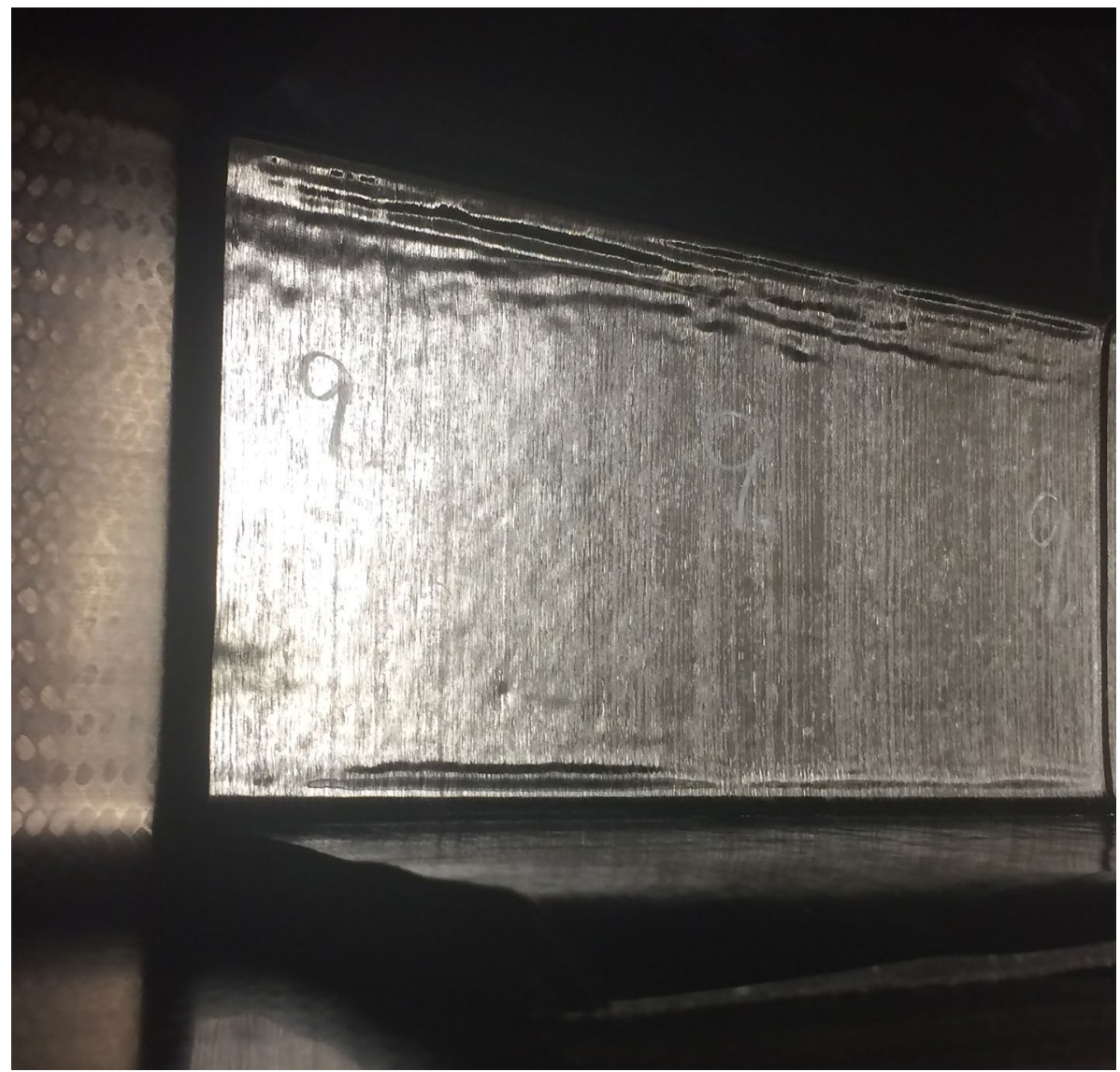

Fig. 11 Inside of the uncured laminate \#9 after forming using tailored laminate temperature and seating in the concave cure tool. The laminate web shows wrinkles, especially by the right-hand side corner (upper region in the figure)

\subsubsection{Temperature Measurements}

Figure 12 shows thermocouple readings from flange positions $\mathrm{F}^{0.25}$ and $\mathrm{F}^{0.75}$ and corner positions $\mathrm{C}^{0.25}$ and $\mathrm{C}^{0.75}$ from the first heating experiment with single-sided heating. The heat-source temperature was $55^{\circ} \mathrm{C}$. Simulation values from the same locations are also shown for comparison. The experimental and simulation results agree within a couple of degrees except for position $\mathrm{F}^{0.25}$ which has a lower heat-up rate in reality compared to the model.

As temperature increases it is possible to see that there is disturbance in the heat-up process. This is particularly evident at about $360 \mathrm{~s}$ where the heat-up rate for $\mathrm{F}^{0.25}$ (which is closest to the heat source) increased more rapidly because of added pressure between the heat source and the laminate and at about $720 \mathrm{~s}$ where insulation was improved. 


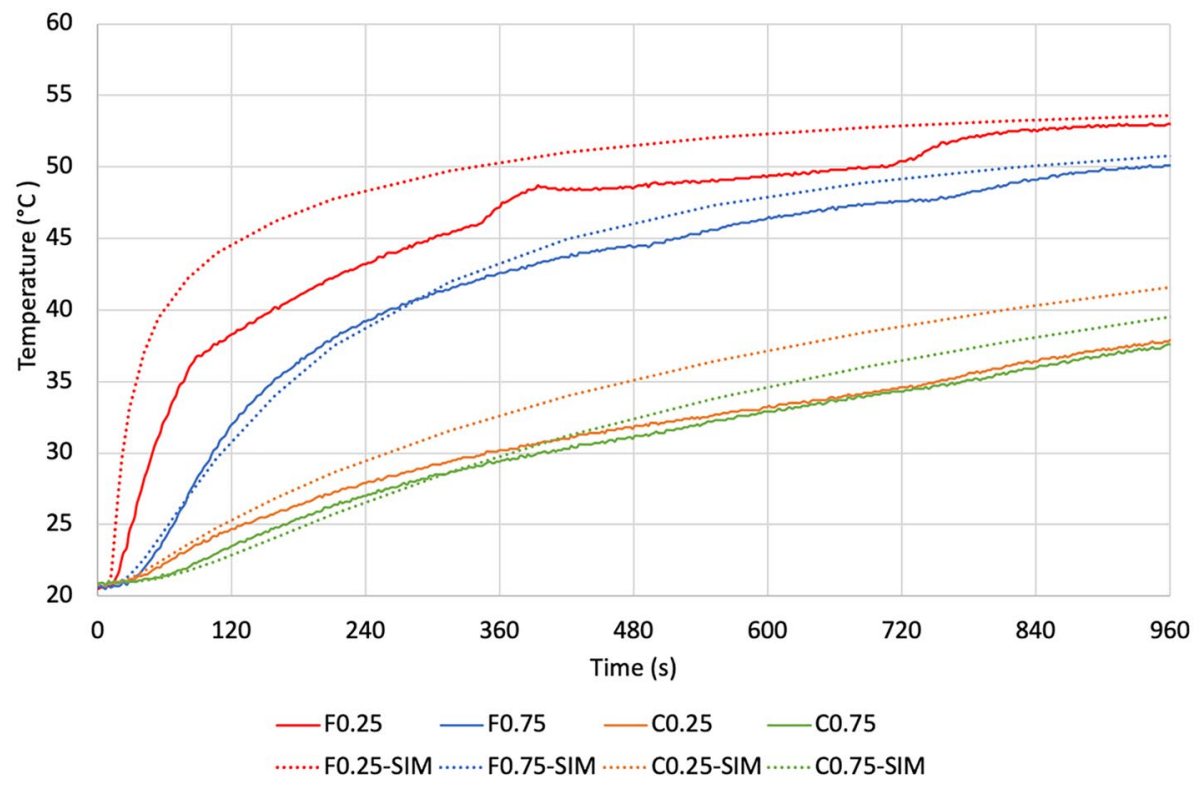

Fig. 12 Thermocouple readings from the first heating trial using single-sided heating. The plot shows temperatures for flange and corner as well as corresponding simulation results. Legend designations (i.e. thermocouple positions) according to Fig. 1

\section{Discussion}

A previous study [5] has shown corner thinning of 14-15\% after standard hot-forming for the exact same laminate as in this study. Measures were there taken to minimise the effects of this by novel compensation of the forming tool shape. The comparable corner thinning after tailored laminate temperature hot-forming in this study is $3-4 \%$. Even with the uncertainty of thickness measurement of soft laminates this is a considerable difference. The reduced thinning results in a better match between the outer corner radius of the formed laminate and the concave cure tool radius. In this study the formed laminate width and outer laminate radii gave a tight fit in the cure tool but without any seating problems. Simulation has shown that the laminates heated with double-sided heating showed the most even temperature in the flanges. After consolidation (during cure) these laminates showed evidence of bridging of the plies and resulting corner thickening. The excess ply length from wrinkles present in sample \#9 have probably helped to reduce the corner bridging. However, these wrinkles are generally not allowed. If the bridging effect is consistent (without having wrinkles in any stage of the process), it can be reduced by compensation of the forming tool shape [5].

It is probably possible to speed up the process even further using a more efficient heat source, e.g. induction or microwave heating. Furthermore, fine-tuning of the heat-up and temperature tailoring can be made by either shifting the position of the upper and lower heat source or having different temperature of these. Then the full potential of the tailored temperature hot-forming process can be utilized. 
In this study the tailored laminate temperature hot-forming process on a convex tool is combined with curing in a concave tool. However, since the thickness variation directly after forming is reduced, the method is suitable also when curing on a convex tool [7]. In both cases, the reduced corner thinning is important.

When heat source temperature is increased the process is more rapid and more careful timing is necessary to maintain the temperature differential between flange and corner. This is also true for other heating techniques, e.g. induction heating. If the heat-up rate can be increased, the timing becomes more critical to maintain the tailored laminate temperature.

With heating of the laminate separated from the forming tool, very little heat is accumulated in the forming tool and equipment. The cool down phase is therefore significantly reduced compared when heating is performed with the laminate on the forming tool.

Moving the uncured and partially heated laminates without causing distortion was not a problem. The unheated area provided enough stiffness for the laminates to stay flat. However, when the heat source temperature was raised from $65{ }^{\circ} \mathrm{C}$ to $70{ }^{\circ} \mathrm{C}$, the heat-up times for double-sided heating was reduced to a point where it becomes difficult to keep up with manual handling of the laminate. Handling will become more complicated and require some equipment as laminate size increases. To flip the laminate up-side down is also easy to do by hand with a small laminate and much more complicated as size increase. This may be mitigated by placement of the heat source.

\subsection{Sensitivity Study}

The experimental process times are slightly shorter than the simulated equivalent for 7 out of 9 samples. This can be due to a slight inaccuracy of both material parameters and process parameters as well as differences in temperature monitoring. In the experiments the laminate temperature is measured at the edge and temperature variation along the sample length is not considered.

The idle phase is important for both the tailored temperature difference between flange and corner and through-thickness temperature difference. Figure 13 shows the effect of a variation of the idle time between 1 and $60 \mathrm{~s}$.

If the idle time is removed (represented by a $1 \mathrm{~s}$ idle time) the temperature difference through the laminate is very high at forming start. This point is indicated with black arrows in Fig. 13, sub-plots $\mathrm{c}$ and d. On the other hand, with $60 \mathrm{~s}$ idle time, the temperature difference is at a minimum for single-sided heating, indicated with a red arrow in Fig. 13, sub-plot c. For this type of heating the through-thickness temperature difference will continue to decrease as the idle time increase. In Fig. 13, subplot d the red arrow indicates the temperature for $60 \mathrm{~s}$ idle time for double-sided heating. In this case, the through-thickness temperature difference has passed a minimum due to heat transfer to the surroundings and some of the temperature tailoring effect is lost. The optimum idle time should be considered in the tailored temperature hot-forming process.

Variation of some other model parameters has been studied to further evaluate the sensitivity of the process. This also shows risks and opportunities. The target temperature of $50{ }^{\circ} \mathrm{C}$ at forming start is common for all simulations. The parameters and total process time for single-sided and double-sided heating are shown in Table 4.

The results of the parameter variation are shown graphically in Figs. 14-17 where single-sided heating is shown in the left-hand plots and double-sided heating in the righthand plots. In these, the plot curve for the lowest heat-up time is shown in black and the 

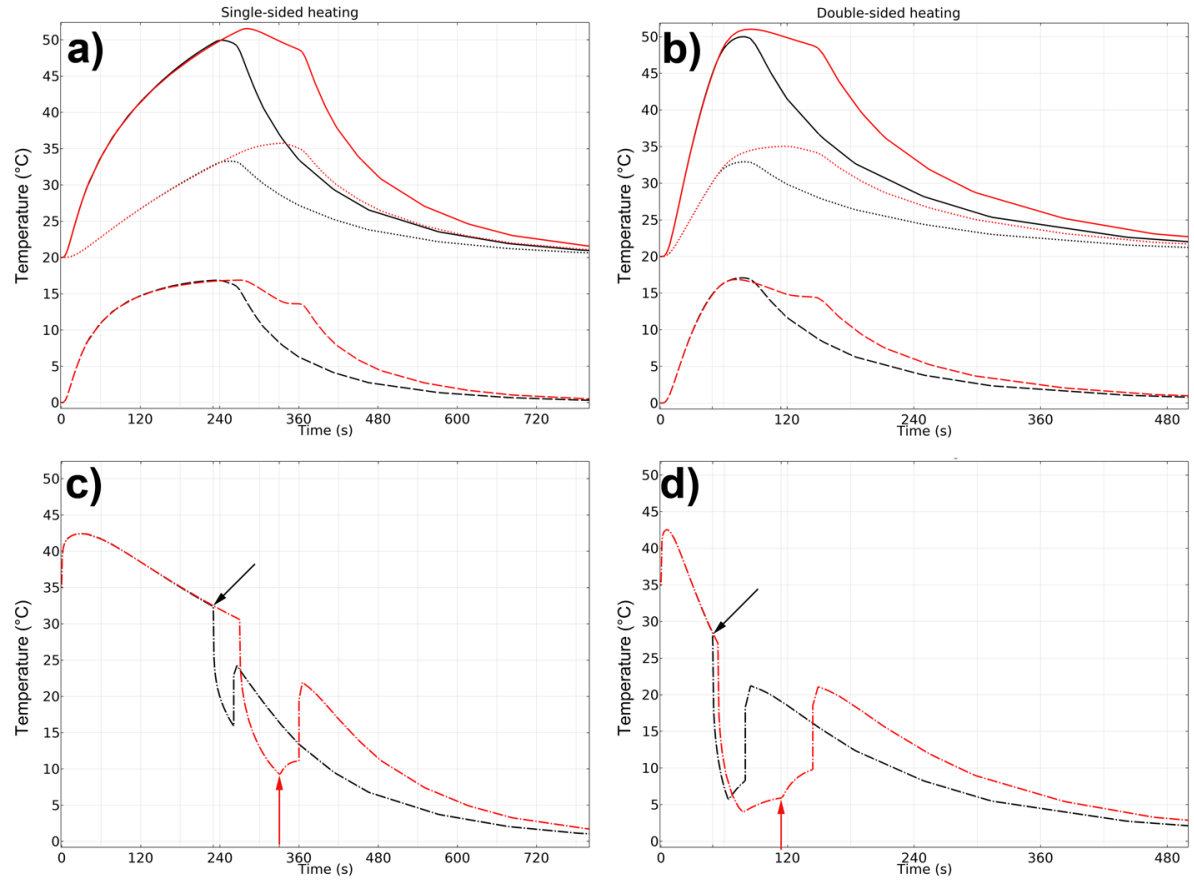

Fig. 13 Simulation result for variation of idle time (IT) from 1 to $60 \mathrm{~s}$. Results for single-sided heating to the left in sub-plot a and $\mathrm{c}$ and for double-sided heating to the right in sub-plots $\mathrm{b}$ and d. Sub-plots a and $\mathrm{b}$ show flange temperature $\mathrm{F}^{0.5}$ with solid lines and corner temperature $\mathrm{C}^{0.5}$ with dotted lines. The resulting tailored forming temperature difference is shown with dashed lines. Sub-plots $\mathrm{c}$ and $\mathrm{d}$ show the maximum temperature variation through the thickness of the laminate at the border between the flange and corner areas with dash-dot lines. Arrows indicating forming start

plot curve for the higher value is shown in red. Flange temperature $\mathrm{F}^{0.5}$ is shown with solid lines and corner temperature $\mathrm{C}^{0.5}$ is shown with dotted lines. The resulting tailored forming temperature difference is shown with dashed lines.

Table 4 Summary of total process time with variation of parameters

\begin{tabular}{|c|c|c|c|c|c|c|}
\hline \multicolumn{4}{|l|}{ Parameter } & \multicolumn{2}{|c|}{ Total process time $[\mathrm{s}]$} & \multirow[t]{2}{*}{ Figure } \\
\hline Description & Baseline value & Variation & Value & Single-sided & Double-sided & \\
\hline Baseline & - & - & - & 474 & 281 & Figure 7 \\
\hline \multirow[t]{2}{*}{ Laminate thickness, LAM_T } & \multirow[t]{2}{*}{$8.4 \mathrm{~mm}$} & $-50 \%$ & 4.2 & 159 & 123 & \multirow[t]{2}{*}{ Figure 14} \\
\hline & & $+50 \%$ & 12.6 & 1060 & 528 & \\
\hline \multirow{4}{*}{$\begin{array}{l}\text { Thermal conductivity coef- } \\
\text { ficient, } k \_33\end{array}$} & \multirow{4}{*}{$\frac{0.350}{\frac{W}{m * K}}$} & $-10 \%$ & 0.315 & 536 & 306 & Figure 15 \\
\hline & & $-5 \%$ & 0.333 & 506 & 294 & N/A \\
\hline & & $+5 \%$ & 0.368 & 462 & 274 & N/A \\
\hline & & $+10 \%$ & 0.385 & 446 & 267 & Figure 15 \\
\hline \multirow[t]{2}{*}{ Heat source temperature, HST } & \multirow[t]{2}{*}{$65^{\circ} \mathrm{C}$} & $-5^{\circ} \mathrm{C}$ & 60 & 599 & 305 & \multirow[t]{2}{*}{ Figure 16} \\
\hline & & $+5^{\circ} \mathrm{C}$ & 70 & 417 & 273 & \\
\hline \multirow{2}{*}{$\begin{array}{l}\text { Forming tool temperature, } \\
\text { FTT }\end{array}$} & \multirow[t]{2}{*}{$20^{\circ} \mathrm{C}$} & $-5^{\circ} \mathrm{C}$ & 15 & 435 & 240 & \multirow[t]{2}{*}{ Figure 17} \\
\hline & & $+5^{\circ} \mathrm{C}$ & 25 & 576 & 387 & \\
\hline
\end{tabular}



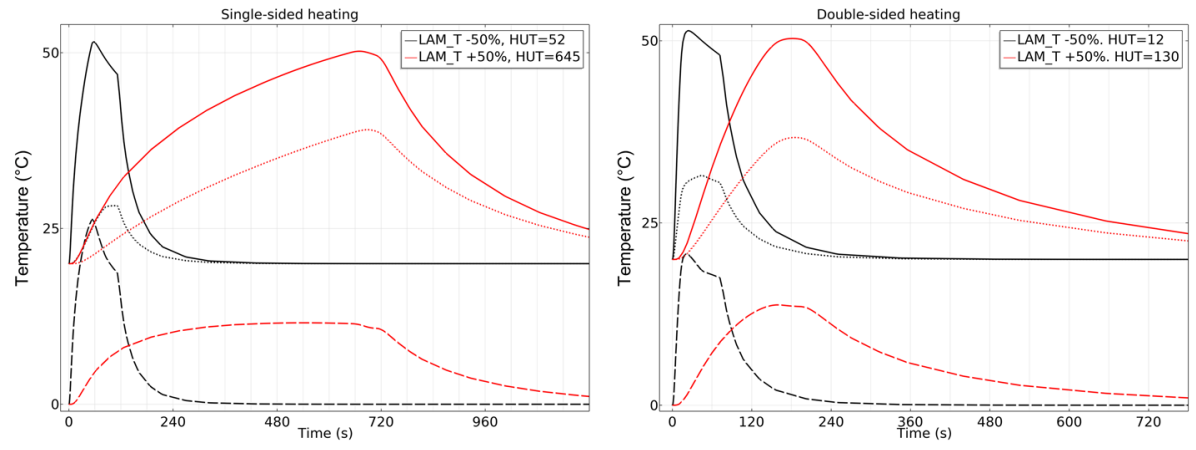

Fig. 14 Laminate thickness (LAM_T) effect on the tailored temperature hot-forming process. Single-sided heating is shown in the left-hand plots and double-sided heating in the right-hand plots. The plot curve for the lowest heat-up time (HUT) is shown in black and the plot curve for the higher value is shown in red. Flange temperature $\mathrm{F}^{0.5}$ is shown with solid lines and corner temperature $\mathrm{C}^{0.5}$ is shown with dotted lines. The resulting tailored forming temperature difference is shown with dashed lines

Both the standard and the tailored temperature hot-forming processes are affected by laminate thickness. In Fig. 14 a variation of the thickness by $\pm 50 \%$ is shown. Thinner laminates result in a greater tailored temperature difference. With double-sided heating a $4.2 \mathrm{~mm}$ laminate can be formed in $2 \mathrm{~min}$ and a $12.6 \mathrm{~mm}$ laminate in $9 \mathrm{~min}$.

$\mathrm{A} \pm 10 \%$ variation of the through-thickness thermal conductivity coefficient, $\mathrm{k} \_33$ is shown in Fig. 15. If this parameter is considered the only uncertainty, $a \pm 6 \%$ change covers the difference in process time between experimental and simulation results in this study.

Increasing the heat source temperature obviously shortens the heat-up time. The overall forming cycle is shortened for both single-sided and double-sided heating, but with less effect for the latter. The tailored temperature difference is 15-18 degrees with single-sided heating and 15-17 degrees with double-sided heating.

If the forming tool temperature is lowered by $5{ }^{\circ} \mathrm{C}$ to $15{ }^{\circ} \mathrm{C}$ the cool-down phase and thus the entire process can be shortened by about $40 \mathrm{~s}$. If the forming tool
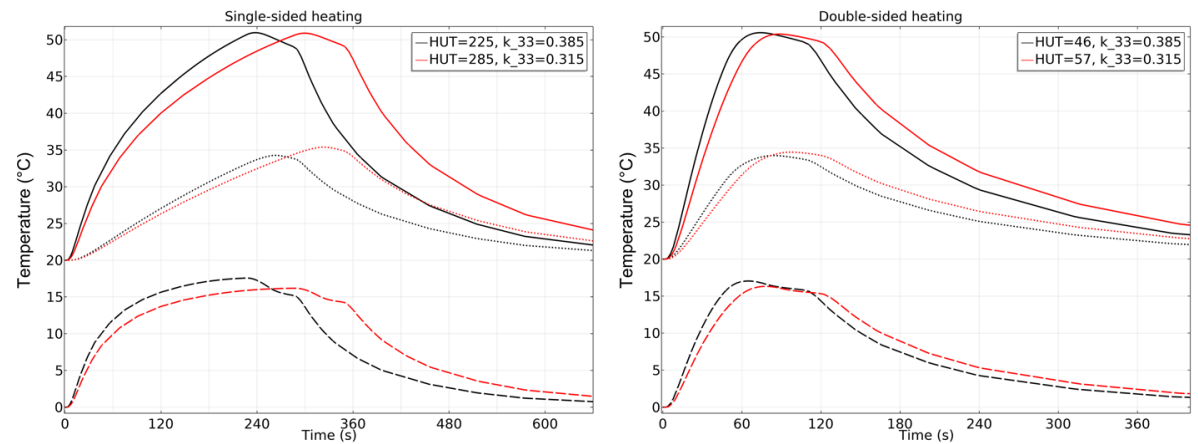

Fig. 15 Variation of the through-thickness thermal conductivity coefficient, k_33 by $\pm 10 \%$. Single-sided heating is shown in the left-hand plots and double-sided heating in the right-hand plots. The plot curve for the lowest heat-up time (HUT) is shown in black and the plot curve for the higher value is shown in red. Flange temperature $\mathrm{F}^{0.5}$ is shown with solid lines and corner temperature $\mathrm{C}^{0.5}$ is shown with dotted lines. The resulting tailored forming temperature difference is shown with dashed lines 

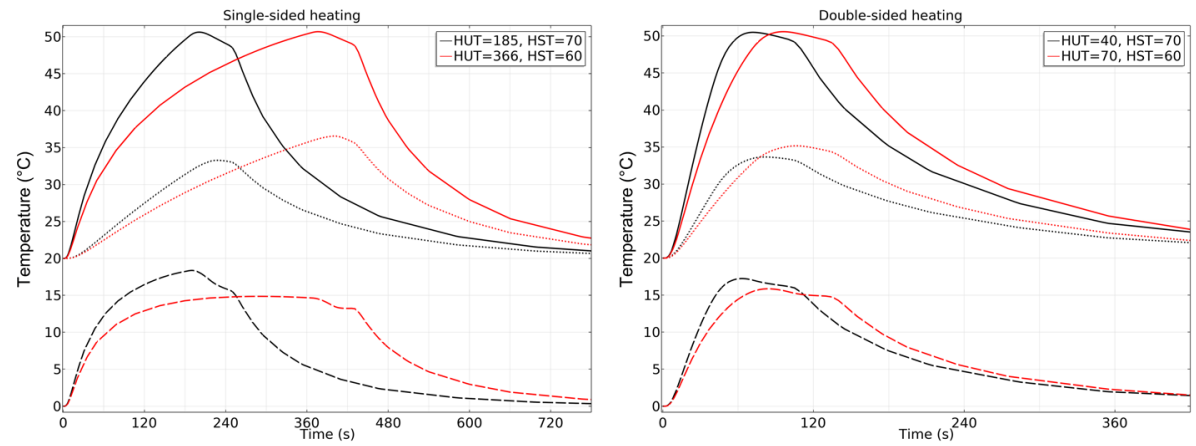

Fig. 16 Effect of varying the heat source temperature (HST) by $\pm 5{ }^{\circ} \mathrm{C}$, i.e. between $60{ }^{\circ} \mathrm{C}$ and $70{ }^{\circ} \mathrm{C}$. Single-sided heating is shown in the left-hand plots and double-sided heating in the right-hand plots. The plot curve for the lowest heat-up time (HUT) is shown in black and the plot curve for the higher value is shown in red. Flange temperature F0.5 is shown with solid lines and corner temperature C0.5 is shown with dotted lines. The resulting tailored forming temperature difference is shown with dashed lines

temperature is increased by $5{ }^{\circ} \mathrm{C}$ to $25{ }^{\circ} \mathrm{C}$ the process time is increased with about $100 \mathrm{~s}$. The targeted temperature difference is unaffected since heating is performed with the laminate separate from the forming tool (unlike the standard hot-forming process).

The model was finally extended with both perfect contact between heat source and laminate and with heat transfer into and out of the laminate dampened by a thin $(25 \mu \mathrm{m})$ plastic film. In the latter case, there was perfect contact between tool and plastic film and between plastic film and laminate. The film, with an isotropic thermal conductivity coefficient $0.4 \mathrm{~W}^{*} \mathrm{~m}^{-1} * \mathrm{~K}^{-1}$, represents a release film (RF) on the laminate. The maximum temperature difference between the cases with and without release film is about a quarter of a degree.
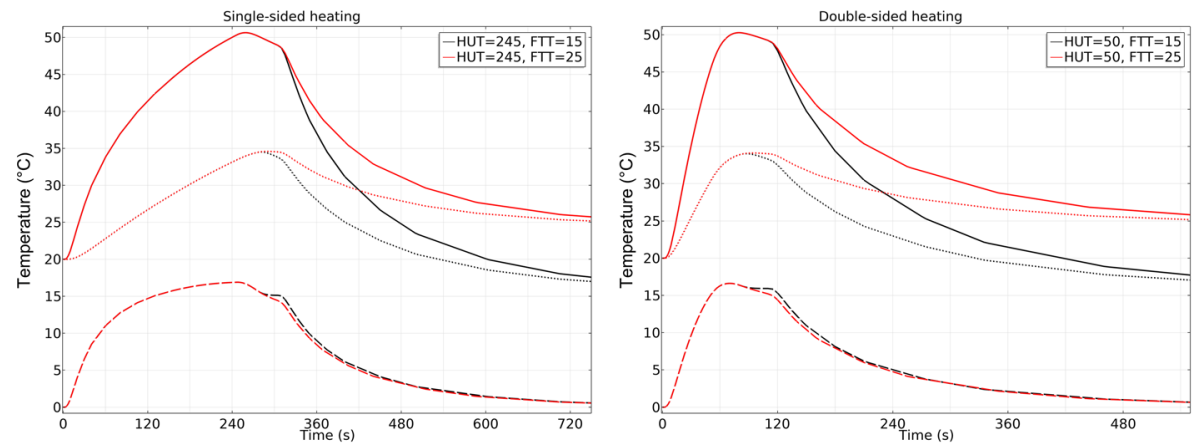

Fig. 17 Effect of varying the forming tool temperature (FTT) by $\pm 5{ }^{\circ} \mathrm{C}$ from $15{ }^{\circ} \mathrm{C}$ to $25{ }^{\circ} \mathrm{C}$. Single-sided heating is shown in the left-hand plots and double-sided heating in the right-hand plots. The plot curve for the lowest heat-up time (HUT) is shown in black and the plot curve for the higher value is shown in red. Flange temperature $\mathrm{F}^{0.5}$ is shown with solid lines and corner temperature $\mathrm{C}^{0.5}$ is shown with dotted lines. The resulting tailored forming temperature difference is shown with dashed lines 


\subsection{Future Work}

The two-dimensional temperature mapping made in the flat condition need to be implemented into a drape forming simulation software, which is not possible today. This would probably improve the resolution of this simulation since the temperature dependent inter- and intra-ply properties are crucial.

Another interesting continuation of this study would be to tailor the laminate temperature in three dimensions for more complex geometries than straight spars. It seems plausible that hot-forming could be improved by actively controlling the temperature over a surface (instead of only in the cross section) to increase formability and/or thickness variation in difficult areas. However, this requires a heat source that is preferably contactfree and optimized for efficient local heating.

\section{Conclusions}

Vacuum-assisted hot-forming with tailored laminate temperature is possible. Properly timed by using simulation, it facilitates an uncured thickness variation between the flat areas and the corner after forming below $4 \%$ in the tested material.

In this study a complete tailored temperature hot-forming cycle of $7.5 \mathrm{~min}$ resulted in very good quality for an $8.4 \mathrm{~mm}$ thick 64 ply quasi-isotropic unidirectional prepreg laminate. This is approximately $85 \%$ reduction of the time needed for the standard hotforming process. The automatically laid-up and hot-formed U-shaped laminates cured in a concave mould with standard bag only on the inside showed a total cured thickness variation as low as $4 \%$ without wrinkles or indications of porosity.

With a maximum thickness tolerance of $8 \%$ a hot-forming process time of 5 min was achieved and 4 min with tendency of process instability. Further tuning of the process can probably give even shorter process times while laminate quality is kept at a very high level.

Acknowledgements Expert advice and feedback from Mikael Petersson at Saab AB were much appreciated.

Funding Open Access funding provided by Royal Institute of Technology. This work was supported by the Swedish Foundation for Strategic Research, grant number ID15-0042, Saab AB and the Swedish Innovation Agency, VINNOVA, via LIGHTer Academy.

\section{Declarations}

Conflicts of Interest/Competing Interests To the knowledge of the authors there are no conflicts of interest or competing interests for this paper.

Data Transparency All material used in this study has been submitted in the manuscript and appendix 1.

Code Availability Not applicable.

Open Access This article is licensed under a Creative Commons Attribution 4.0 International License, which permits use, sharing, adaptation, distribution and reproduction in any medium or format, as long as you give appropriate credit to the original author(s) and the source, provide a link to the Creative Commons licence, and indicate if changes were made. The images or other third party material in this article are included in the article's Creative Commons licence, unless indicated otherwise in a credit line to the material. If material is not included in the article's Creative Commons licence and your intended use is not permitted by statutory regulation or exceeds the permitted use, you will need to obtain permission directly from the copyright holder. To view a copy of this licence, visit http://creativecommons.org/licenses/by/4.0/. 


\section{Appendix}

\section{Appendix 1 - Cross-section Micrographs (Reduced Resolution)}

\section{References}

1. Hallander, P.: Towards defect free forming of multi-stacked composite aerospace components using tailored interlayer properties. Doctoral Thesis in Aerospace Engineering, Stockholm, Sweden . ISBN 9789175959504 (2016)

2. Hallander, P., Grankäll, T., Eriksson, M., Peterson, M., Åkermo, M.: Using tailored temperature variations to obtain flawless forming of multi-stacked UD prepreg. Journal of Composite Materials. https:// doi.org/10.1177/0021998320924714

3. Sun, J., Gu, Y., Li, M., Ma, X., Zhang, Z.: Effect of forming temperature on the quality of hot diaphragm formed C-shaped thermosetting composite laminates. J. Reinf. Plast. Compos. 31(16), 10741087 (2012)

4. Pandey, R.K., Sun, C.T.: Mechanisms of wrinkle formation during the processing of composite laminate. Composite Science and Technology 59, 405-417 (1999)

5. Grankäll, T., Hallander, P., Åkermo, M.: Geometric compensation of convex forming tools for successful final processing in concave cure tools - An experimental study. Compos. A Appl. Sci. Manuf. 116, 187-196 (2019)

6. Hallander, P., Sjölander, J., Petersson, M., Andersson, T., Åkermo, M.: Fast forming of multi-stacked UD prepreg using a high-pressure process. Polymer Composites. 40(9):3550-3561 (2019)

7. Sjölander, J.: Improving forming of aerospace composite components through process modelling. Doctoral Thesis in Aerospace Engineering, Stockholm, Sweden, ISBN 978-91-7729-881-6 (2018)

8. Bian, X.X., Gu, Y.Z., Sun, J., Li, M., Liu, W.P., Zhang, Z.G.: Effects of Processing Parameters on the Forming Quality of C-Shaped Thermosetting Composite Laminates in Hot Diaphragm Forming Process. Appl. Compos. Mater. 20(5), 1-19 (2012)

9. Farnand, K., Zobeiry, N., Poursartip, A., et al.: Micro-level mechanisms of fiber waviness and wrinkling during hot drape forming of unidirectional prepreg composites. Compos. A 103, 168-177 (2017)

10. Kappel, E., Albrecht, M.: A controlled recipient evacuation process to form composite profiles from flat multi-angle prepreg stacks - infrastructure and C-profile verification. Advanced Manufacturing: Polymer \& Composites Science, DOI:https://doi.org/10.1080/20550340.2019.1660455

11. Brillant, M., Hubert, P.: Modelling and characterization of thickness variations in L-shape out-of-autoclave laminates. In; 18th International Conference on Composites Materials, Jeju, South Korea (2011)

12. Levy, A.: Hubert P. Vacuum-bagged composite laminate forming processes: Predicting thickness deviation in complex shapes, Composites: Part A 126, 105568 (2019)

13. Dodwell, T.: Internal wrinkling instabilities in layered media. Philos Mag. 1-19 (2015)

14. Dodwell, T.J., Butler, R., Hunt, G.W.: Out-of-plane ply wrinkling defects during consolidation over an external radius. Compos. Sci. Technol. 105, 151-159 (2014)

15. Belnoue, J., Nixon-Pearson, O., Thompson, A., Ivanov, D., Potter, K., Hallett, S.: Consolidationdriven defect generation in thick composite parts. Journal of Manufacturing Science and Engineering. 140:071006-1 (2018) https://doi.org/10.1115/1.4039555

16. Hassan, M.H., Othman, A.R.: Contribution of processing parameters on void content in the vacuum bagging configurations of L-shaped composite laminates. The International Journal of Advanced Manufacturing Technology. 93(1), 1333-1345 (2017)

17. Ma, Y., Centea, T., Nutt, S.R.: Defect reduction strategies for the manufacture of contoured laminates using vacuum BAG-only prepregs. Polym. Compos. 38(9), 2016-2025 (2017)

18. Hassan, M.H., Othman, A.R., Kamaruddin, S.: A review on the manufacturing defects of complexshaped laminate in aircraft composite structures. The International Journal of Advanced Manufacturing Technology. 91(9), 4081-4094 (2017)

19. Fernlund, G., Griffith, J., Courdji, R., Poursartip, A.: Experimental and numerical study of the effect of caul-sheets on corner thinning of composite laminates. Compos. A 33(3), 411-426 (2002)

20. COMSOL Multiphysics® v. 5.5. www.comsol.com. COMSOL AB, Stockholm, Sweden

21. Aniform Software. AniForm Engineering B.V. www.aniform.com

22. Burger, N., Laachachi, A., Ferriol, M., Lutz, M., Toniazzo, V., Ruch, D.: Review of thermal conductivity in composites: Mechanisms, parameters and theory. Prog. Polym. Sci. 61, 1-28 (2016)

23. Hind, S., Robitaille, F.: Measurement and Modelling of in-Plane and Transverse Thermal Conductivity in Tape Prepreg, Non-Woven and Woven Textile Composites. In: Recent Advances in Textile 
Composites - Proceedings of the 9th International Conference on Textile Composites: (TEXCOMP9). DEStech Publications p. 12008$)$

24. Bard, S., Schönl, F., Demleitner, M., Altstädt, V.: Influence of Fiber Volume Content on Thermal Conductivity in Transverse and Fiber Direction of Carbon Fiber-Reinforced Epoxy Laminates. Materials (Basel, Switzerland) 12(7) (2019)

25. Joven, R., Minaie, B.: Thermal properties of autoclave and out-of-autoclave carbon fiber-epoxy composites with different fiber weave configurations. J. Compos. Mater. 52(29), 4075-4085 (2018)

26. Farmer, J., Covert, E.: Transverse thermal conductance of thermosetting composite materials during their cure. J. Thermophys. Heat Transfer 8(2), 358-365 (1994)

27. Scott, E.P., Beck, J.V.: Estimation of Thermal Properties in Carbon/Epoxy Composite Materials during Curing. J. Compos. Mater. 26(1), 20-36 (1992)

28. Hexcel, HexPly® $6376,175^{\circ} \mathrm{C}$ curing epoxy matrix. Product Data Sheet. https://www.hexcel.com

29. https://www.gom.com/metrology-systems/atos/atos-triple-scan.html

30. https://www.gom.com/3d-software/gom-inspect.html

31. https://www.olympus-ims.com/en/microscope/bx $53 \mathrm{~m} /$

32. https://www.olympus-ims.com/en/microscope/stream2

Publisher's Note Springer Nature remains neutral with regard to jurisdictional claims in published maps and institutional affiliations. 